\title{
BIM Technology Application in the Exploration of Super High-rise Office Building Project in Civil Construction
}

\author{
Yufeng $\mathrm{Li}^{1, \text { a }}$, Zheng Gao ${ }^{2, b}$ and Xiaofeng Zhang ${ }^{3, \mathrm{c}}$ \\ ${ }^{1}$ NO.2 Ganping Road,Nanming District,Guiyang City,China \\ ${ }^{2}$ NO.9 Kechuangsijie Road,Yizhuang economic development District,Beijing City, China \\ ${ }^{3}$ NO.9 Wuxianbei Road,Caidian District,Wuhan City,China

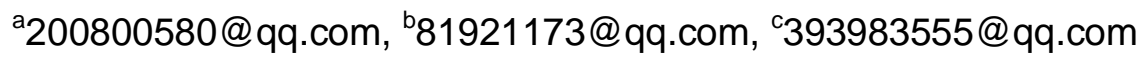

Keywords: BIM; 5D virtual technology; Collision detection; Zero yard; Deepening

Abstract. Guangzhou Pearl River New City J2-5 project east faces Xian Cun Road, south close to the Ritz Carlton Hotel, west close to Guangzhou East Tower, and north close to Global Metroplaza. It uses BIM technology to deepen its work for the construction drawings and construction program to previously find and solve the problems existing in the construction, make full use of external conditions and resources, exchange the traditional site processing template, steel, masonry and other professional engineering into field processing, solve narrow space, achieve the bulk material piled up, processing and other issues, ensuring project quality, safety, duration, benefit and other major control objectives.

\section{Introduction}

Guangzhou Pearl River New City office J2-5 project is positioned as the central core business district for catering, banquets, high-end office buildings and supporting facilities. The total area of the project is $7,470 \mathrm{~m}^{2}$, with a total construction area of $150,085 \mathrm{~m}^{2}$, including the ground floor area $123,783 \mathrm{~m}^{2}$, underground construction area $26,302 \mathrm{~m}^{2}$. The framework form is core tube structure, 53 floors on the ground, 4 floors underground, total building height is $252.10 \mathrm{~m}$. Where the basement is underground garage, 1-5 floors are restaurant, banquet hall and supporting facilities, 6-53 floors are office space and supporting facilities. Rendering of the project is shown in Fig. 1.

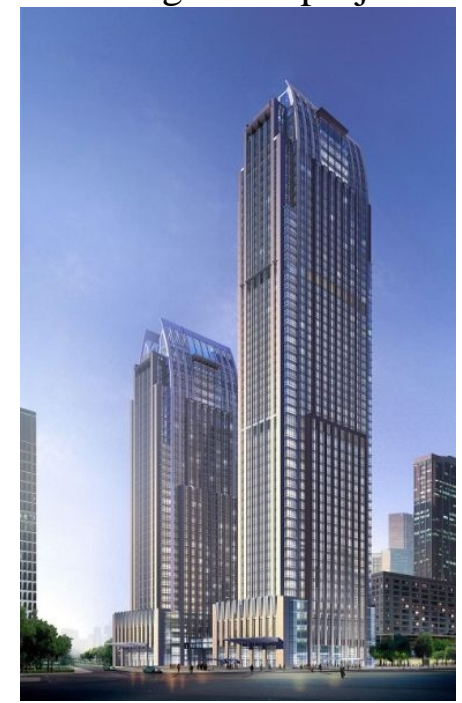

Fig.1 Rendering of Guangzhou Pearl River New City office J2-5 project

BIM application on $\mathrm{J} 2-5$ project is basic application platform mainly on the establishment of BIM 5D software as the core, through civil engineering modeling, modeling of steel, electrical and mechanical modeling, 3D models to the site deepening design. Application of BIM 5D model to carry out an integrated model of turnover, the construction of dynamic simulation in order to achieve harmonization of management on cost, quality, schedule. The project is large and tight deadlines. 
Available construction site is extremely narrow, flat organization and management are difficult. BIM construction technology is introduced for the project based on these factors as follows:

a) The construction site is narrow. The project lies in the busiest section of Guangzhou CBD Central Business District, the entire construction site sidelines are red lines. Above $300 \mathrm{~m}$ buildings in the west and north sides are being built, city roads in the east, the five-star hotels do business in the south, available space is extremely narrow. How to reasonably and efficiently use the limited venues to minimize the negative impact to the surrounding brought by the construction, is the key to work smoothly for the project.

b) Foundation construction is complex. The most important feature of this project excavation pit is large-scale, ultra-deep excavation, and complex inner support beams. Besides, the surroundings is more complex and groundwater level is high. Therefore, excavation and sealing curtain requirements are relatively high. At the same time, the construction node is also complicated. Civil engineering, water supply and drainage, HVAC, electrical and other professional cross strength, prone to conflict which should be resolved in advance, to avoid reworking in later period.

c) Technology management. The traditional drawing reviewing will be checked profssionally based on two-dimensional drawings. Time is limited and volum is large, and it is difficult to find all the problems into optimizating drawings, still to be processed in later period. Technical tests only rely on flat two-dimensional drawings which cannot fully and completely finish operational tests to subcontracting group and operation workers, workers could not understand part of a complex node leading to some blind tests on work.

\section{Application of BIM Technology}

\section{Coordination.}

\section{D Virtual Technology.}

5D concept: $5 \mathrm{D}=$ three-dimensional space + schedule + cost

The project selects Germany RIB Group's iTWO 5D management platform to carry out BIM technology application. iTWO 5D virtual construction technology combines 3D models with field schedule and cost plan, analyzes schedule and cost plan on real-time, to achieve the dynamic management costs control.

\section{Inner support Collision Detection.}

The basement project schedule is very tight. The project department decides not to demolish the fundation inner support until main structure construction reaches to \pm 0 . According to the special circumstance of inner support being removed in later period, collision conflict point of basement structure and inner support is required to pinpoint in advance to determine the construction scheme and early organization, so as to ensure the smooth implementation of the construction site, reducing rework and secondary construction, guaranteeing period. Through on-site investigation, BIM model is established based on construction drawings. BIM collision detection and visualization techniques are used for collision detection from basement structure and inner support. As is shown in Fig.2, 72 collision points in total are detected, among them 7 collision points can be reserved to treat, 33 collision points require mechanical removal process, and 32 collision points can be avoided by optimizing drawings. Coordination and organization in advance totally save 14 days duration, and directly save project expenditure about 439,000 yuan.

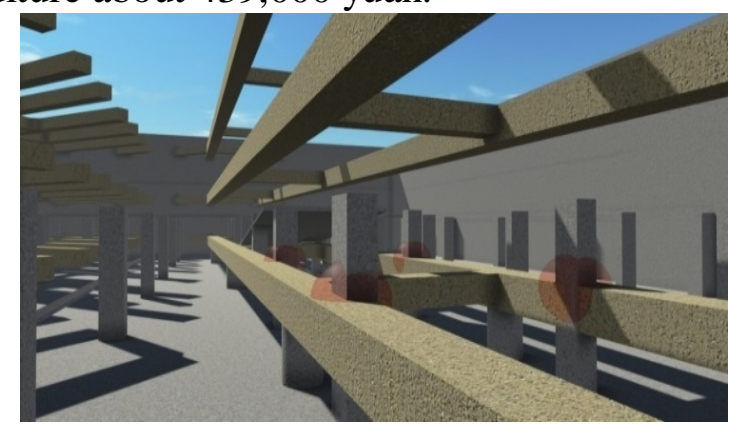

Fig. 2 Inner support collision detection model 


\section{Integrating Pipeline and Reserving Hole Technology.}

BIM collision detection and visualization technologies are used for collision detection to the secondary structure and pipeline in the basement of this project phase. 549 collision points in total are detected. A clear position and size of hole are reserved by optimizing pipeline distribution(Figure 7). The Basement masonry wall pipe reserves hole volume 10.6 cubic meters in total, directly saves construction costs 18,020 yuan totally, avoids wasting materials caused by the secondary excavation and civilized construction.

\section{Optimization.}

\section{"Zero" Yard Technology.}

The construction site is extremely narrow. The only construction site is provided to piled up material, processing and crane transportation in the north. It covers approximately 427.2 square meters, which is only $5.72 \%$ of the total project area, thus affects not only the material to pile up and process, but also seriously affects personnel living conditions and office quality from the site.

BIM technology meticulously deepens its work to construction drawings and construction scheme, identifies in advance and solves problems existing in the construction, makes full use of off-site professional processing conditions and resources to exchange the traditional site processing template, steel, masonry and other professional engineering into off-site processing. According to the concept of logistics management for materials entering site program, it makes sure to deliver materials in batches to the construction working places on time, to achieve goals that construction site does not need to set up a professional yard, does not require on-site processing, without secondary transfer of research ideas to deal with the adverse effects caused by lack of space, so that unfavorable factors turn into favorable factors to actively and effectively achieve controlling objectives. The illustration of off-site professional processing can be shown in Fig. 3.

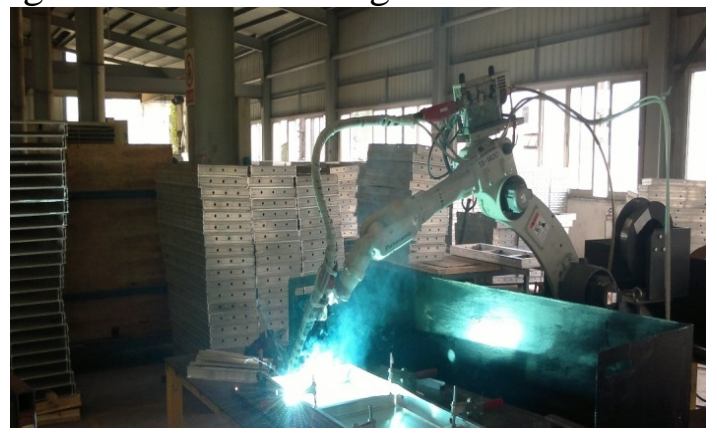

\section{Steel Structure Deepening.}

Fig. 3 Off-site professional processing

To provide the necessary basis for accurate off-site processing and construction, to timely response to the various parties involved in the project about off-site processing and on-site construction existing problems and possible solutions, to ensure project progress and quality, to avoid unnecessary economic losses, we previously establish BIM model which is used to deepen design for professional engineering according to actual needs, based on the construction drawings and construction programs By entering the BIM model to input, extract, update and modify information, many conflicts from the process of deepening design drawings, programs and on-site construction are efficiently solved, to ensure deepening design to accurately reflect the design intent and the effect of reduction to complement and improve the original design deficiencies. The BIM deepen process of steel structure is shown in Fig. 4. 


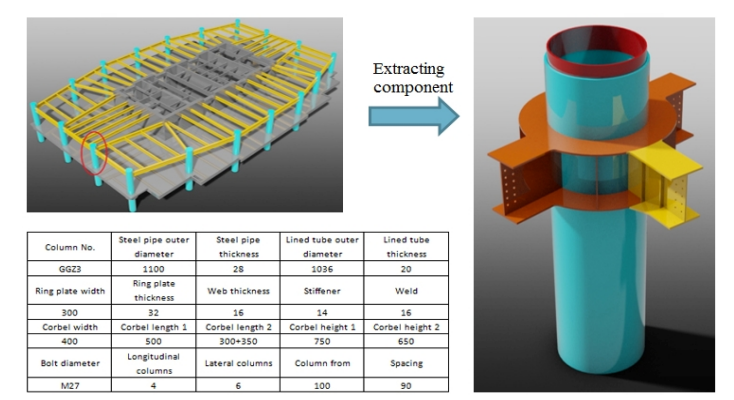

\section{Visual Resistance.}

Fig. 4 Steel Structure BIM deepening flowchart

Technical Tests.

BIM model can accurately reflect the position of each reserved hole, to ensure proper installation of pipelines and other reserved hole position and improve project quality through the model for on-site construction personnel technical tests. The technical test process can be shown in Fig. 5.

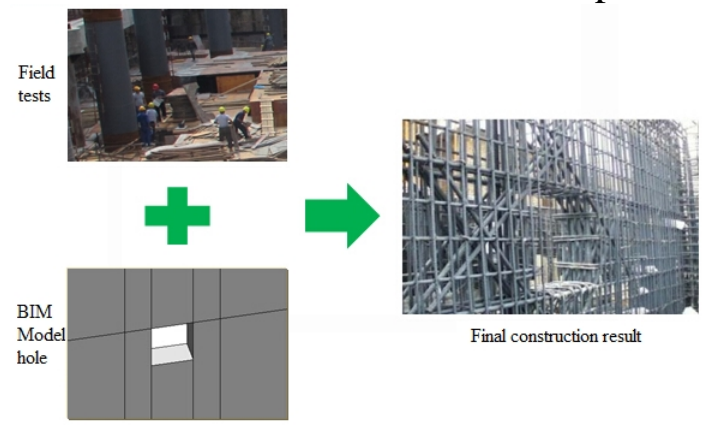

Fig. 5 Technical tests

\section{Conclusion}

As the project under tight deadlines, restricted construction site and other factors, project quality, safety, duration and other basic objectives are difficult to be guaranteed. By taking advantage of the organization and the process guidance of BIM technology in advance, we identify and solve all kinds of problems existing in construction, thus shortening the duration, reducing cost, improving efficiency and achieving to positively and effectively control objectives of the project, strengthening project safety, quality and dynamic supervision. The construction works on the study and practice of BIM technology, has accumulated valuable data and experience, providing reference for the future construction of similar projects.

\section{References}

[1] Richard See, Managing Director and Digital Alchemy. Building Information Models and Model Views[J].Journal of Building Information Modeling(JBIM),Fall 2007

[2] Goldberg, H. Edward . The Building Information Model. Trade Publication, Vol.21-11 (2014), p. 56

[3] T Hartmann, HV Meerveld, N Vossebeld, A Adriaanse. Aligning building information model tools and construction management methods. Automation in Construction. Vol.22-3 (2012), P. 605-613

[4] V Faghihi, KF Reineschmidt, JH Kang. Construction scheduling using Genetic Algorithm based on Building Information Model, Expert Systems with Applications, Vol. 41-16 (2014), P. 7565-7578

[5] J Jones. The importance of BIM. CIVIL ENG, Vol. 84-5 (2014), P. 66-69 